\title{
Environmentally Benign Adsorption Materials for Removing Arsenic from Aquatic Environment
}

\author{
Katsutoshi Inoue1, Hiroyuki Harada ${ }^{2}$, Kedar Nath Ghimire ${ }^{3}$, Biplob Kumar Biswas ${ }^{4}$, \\ Hidetaka Kawakita1, Keisuke Ohto ${ }^{1}$ \\ ${ }^{1}$ Department of Applied Chemistry, Faculty of Science \& Engineering, Saga University, Saga, Japan \\ ${ }^{2}$ Department of Environmental Science, Prefectural University of Hiroshima, Shobara, Japan \\ ${ }^{3}$ Central Department of Chemistry, Tribhuvan University, Kathmandu, Nepal \\ ${ }^{4}$ Department of Chemical Engineering, Jessore University of Science and Technology, Jessore, Bangladesh \\ Email: ka noko1921@gmail.com
}

How to cite this paper: Inoue, K., Harada, H., Ghimire, K.N., Biswas, B.K., Kawakita, H. and Ohto, K. (2018) Environmentally Benign Adsorption Materials for Removing Arsenic from Aquatic Environment. $A d$ vances in Materials Physics and Chemistry, 8, 51-70.

https://doi.org/10.4236/ampc.2018.81005

Received: December 14, 2017

Accepted: January 26, 2018

Published: January 29, 2018

Copyright (c) 2018 by authors and Scientific Research Publishing Inc. This work is licensed under the Creative Commons Attribution International License (CC BY 4.0).

http://creativecommons.org/licenses/by/4.0/

\begin{abstract}
Adsorptive removal of arsenic using adsorption gels prepared from orange and apple juice residues was reviewed by summarizing the authors' previous papers. Orange and apple juice residues contain a large amount of pectin, partly methyl-esterified pectic acid, which exhibits high affinity for high-valent metal ions such as iron(III), rare earths(III) and zirconium(IV). Anionic species of arsenic(III, V) are effectively and selectively adsorbed on pectic acid gel via loading these high-valent metal ions. Raw orange juice residue was saponified using calcium hydroxide to improve the loading capacity for these metal ions. It was found that zirconium(IV) exhibits the most suitable adsorption behaviors for arsenic(III, V). Similar result was obtained also for apple juice residue. An actual sample of acid mine drainage from the Horobetsu mine which contained a high concentration of iron and low concentration of arsenic, was tested using the adsorption gel prepared from orange juice residue and the results were compared with those from the current treatment process based on coprecipitation with iron hydroxide. The new process using the abovementioned adsorption gel was proposed for treatment of such acid mine drainage.
\end{abstract}

\section{Keywords}

Adsorbents, Arsenic, Orange Wastes, Removal, Aquatic Environment

\section{Introduction}

Arsenic is an element belonging to group 15, the nitrogen family, in the periodic 
table together with nitrogen, phosphorus, antimony, and bismuth. Its main valencies are 3 and 5 and it exists as oxo-anions, arsenate and arsenite, respectively, in nature. Although organic arsenic compounds contained in various marine products such as fishes and sea-weeds are non-toxic and have been eaten by human beings since ancient times, inorganic arsenic is toxic, and arsenite is more toxic than arsenate. Soluble arsenite and arsenate have immediate toxic effects. Long-term exposure to arsenic in drinking water can cause cancer of the skin, lungs, bladder and kidney [1]. Since arsenic is a relatively abundant element, with a content of around $1.5 \mathrm{mg} \cdot \mathrm{kg}^{-1}$ or $0.0005 \%$ in the earth's crust, there are many districts where high content of arsenic occurs in soils and subsoil waters. It is introduced into water not only through natural sources such as volcanic emissions, dissolution of mineral ores, and atmospheric decomposition etc. [2] but also through anthropogenic sources such as non-ferrous smelting, petroleum-refining, fossil fuel power plants [3] and so forth. Naturally occurring arsenic is of great concern in some regions of Bangladesh, India, Nepal and China, where ground waters contaminated with arsenic have been used as drinking water. In these areas, hazardous concentrations of arsenic have appeared as a result of strong water-rock interactions and the physical and geochemical conditions for arsenic mobilization in aquifers [4]. Additionally, acid mine drainage containing arsenic is also a serious environmental problem in some area, and this will be mentioned in detail later. Since 1993, the World Health Organization (WHO) has recommended a maximum contaminant level for arsenic of $10 \mu \mathrm{g} \cdot \mathrm{dm}^{-3}$ in drinking water. In order to clear such environmental standards for arsenic, numerous treatment techniques such as co-precipitation, ion exchange, ultrafiltration, and adsorption have been proposed and some of them have been used on a commercial scale.

The main conventional method for arsenic removal has been coprecipitation using lime and ferric compounds such as ferric chloride, in which arsenate and arsenite anions are adsorbed onto precipitates of ferric hydroxide after $\mathrm{pH}$ adjustment using lime and coagulated using trace amounts of coagulating agents such as polyacrylamide to form stable flocs for smoothing filtration [5]. As a typical example of such precipitation process, Scheme 1 shows the flowsheet for the removal of arsenic from acid drainage from a closed sulfur mine at Horobetsu in Hokkaido, Japan [6]. The acid drainage effluent contains $336 \mathrm{mg} \cdot \mathrm{dm}^{-3}$ total iron, of which $294 \mathrm{mg} \cdot \mathrm{dm}^{-3}$ is ferrous iron, $7.88 \mathrm{mg} \cdot \mathrm{dm}^{-3}$ arsenic and 0.16 $\mathrm{mg} \cdot \mathrm{dm}^{-3}$ lead; its $\mathrm{pH}$ is as low as 1.9 and the flow rate is as large as $3.78 \mathrm{~m}^{3} \cdot \mathrm{min}^{-1}$ [7]. By the treatment shown in this flowsheet, the $\mathrm{pH}$ is increased to 7.4 and the arsenic concentration is lowered to $0.018 \mathrm{mg} \cdot \mathrm{dm}^{-3}$, clearing the Japanese effluent standard $\left(0.1 \mathrm{mg} \cdot \mathrm{dm}^{-3}\right)$. In this process, iron present is precipitated by adding lime at the first five tanks and slaked lime at the last three tanks, as ferrous and ferric hydroxides, onto which arsenate and arsenite are adsorbed and coprecipitated, resulting in the generation of a large amount of sludge containing arsenic, which is dumped at special dumping site. However, the total cost of this treatment is as expensive as around 4 million USD per year. Consequently, more 


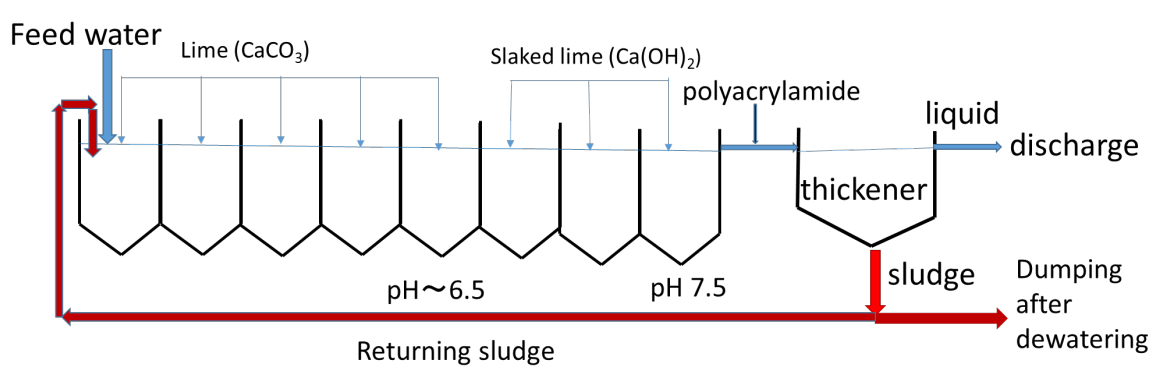

Scheme 1. Flowsheet of the process for neutralization and removal of arsenic from acid drainage at Horobetsu closed sulfur mine in Hokkaido, Japan [6].

economical and more environmentally benign treatment processes are strongly required.

For the adsorptive removal of anionic species of arsenic, the use of cation exchange materials such as strongly acidic cation exchange resins loaded with high-valent metal cations such as ferric ions exhibiting a high affinity for the anionic species in question has been proposed [8]. The mechanism of adsorption of the dihydrogen arsenate ion $\left(\mathrm{H}_{2} \mathrm{AsO}_{4}^{-}\right)$on a sulfonic acid-type strongly acidic cation exchange resin loaded with ferric ion $\left(\mathrm{Fe}^{3+}\right)$ is shown schematically in Scheme 2 as a typical example. In this case, among the 3 positive charges on the ferric ion, only one is neutralized by a sulfonic acid functional group; it is difficult for the other sulfonic groups to approach the ferric ion because of the strong steric hindrance of crosslinked matrices, i.e. crosslinked polystyrene in this case. The other 2 positive charges on the ferric ion are neutralized by anionic species in the aqueous solution such as hydroxyl ions. Such anionic species are substituted by other anionic species such as arsenate and arsenite. Consequently, these anionic species can be easily adsorbed and desorbed by changing the $\mathrm{pH}$.

For the purpose of developing more environmentally benign techniques for removing and recovering these anionic species, we have studied environmentally benign new adsorption materials using natural biomass wastes instead of synthetic materials such as ion exchange resins produced from petroleum.

There are a variety of natural organic polymeric materials with functionalities for adsorbing cationic metal ions in nature: acidic polysaccharides such as alginic acid and pectic acid [9], basic polysaccharides such as chitosan [10] and various proteins [11]. Furthermore, adsorption using various biomass wastes has attracted great attention in recent years [12].

\section{Adsorption of Metal Ions on Acidic Polysaccharides}

Scheme 3 shows the chemical structures of some polysaccharides, among which alginic acid and pectic acid are typical acidic polysaccharides containing carboxylic acid functional groups. Alginic acid is present as a calcium(II) complex in the well-known egg-box structure, as shown in Scheme 4, in sea-weeds as a major component together with cellulose. On the other hand, pectic acid exists in fruits such as oranges and apples as pectin, partly methyl-esterified pectic acid as 


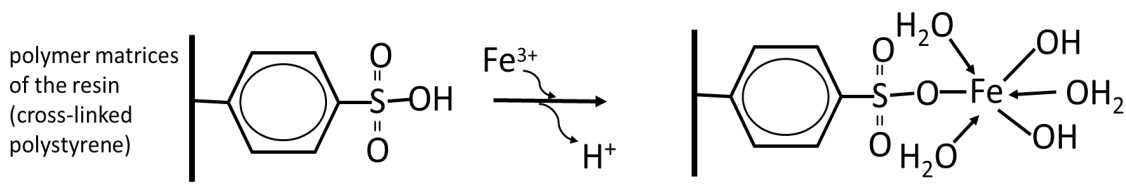

sulfonic acid type of strongly cation exchange Fe-loaded cation exchange resin acidic cation exchange resin reaction

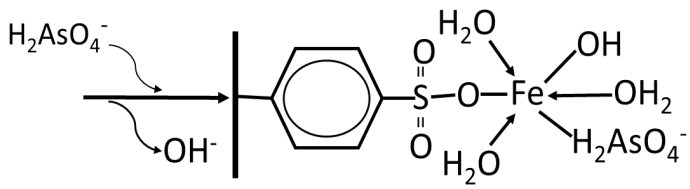

anion exchange

reaction

Scheme 2. Mechanism of arsenate on iron (III)-loaded strongly acidic cation exchange resin.
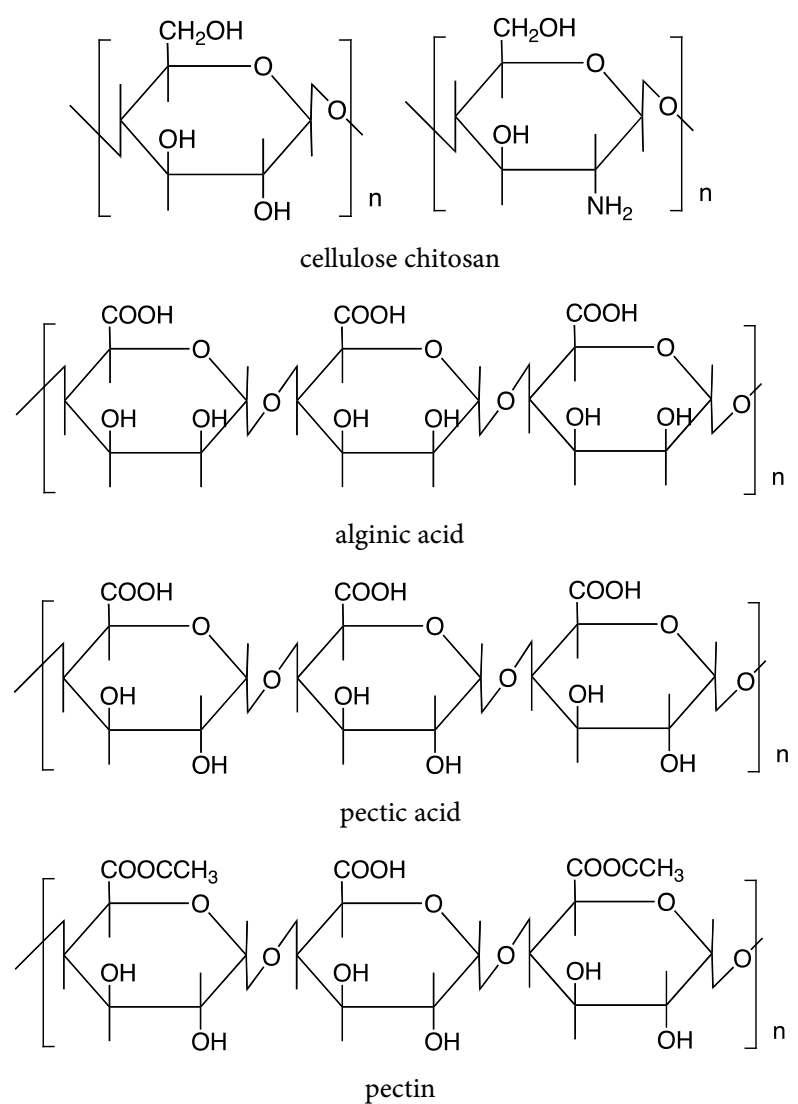

Scheme 3. Chemical structures of some polysaccharides.

also shown in Scheme 3. It is easily saponified by alkalis such as sodium hydroxide and calcium hydroxide, as shown in Scheme 5. As shown in Scheme 4, divalent metal ions such as calcium(II) form stable 5-membered chelates with alginic acid and pectic acid by coordination with the oxygen atoms of the carboxylic groups and pyranose rings of the polysaccharide, as well as the ether oxygens between the pyranose rings. 


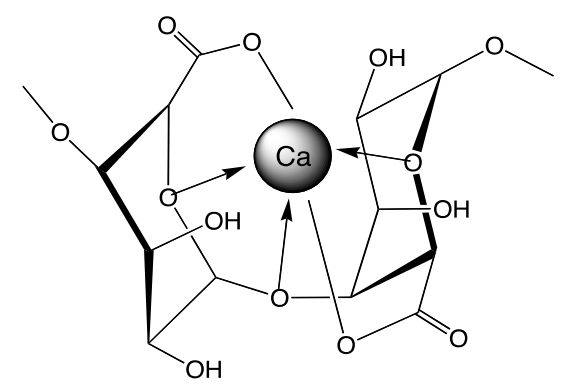

Scheme 4. Structure of calcium(II) alginate (egg box structure).

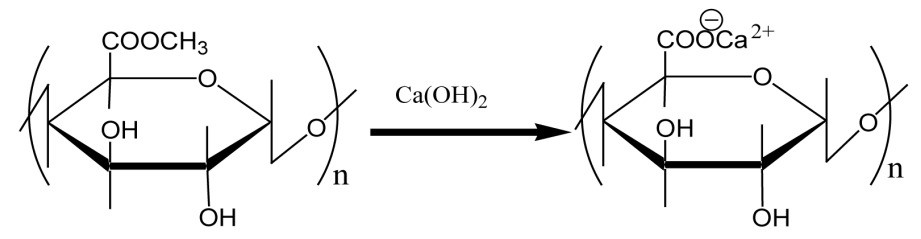

Scheme 5. Saponification reaction of pectin using calcium hydroxide.

Figure 1 shows the \% adsorption of some metal ions on pectic acid crosslinked using formaldehyde from aqueous solution at equilibrium at various $\mathrm{pH}$ values [13], where \% adsorption denotes the extent of adsorption and is defined by the following equation.

$\%$ adsorption $=$

$\{($ initial concentration - concentration after adsorption $) /$ initial concentration $\} \times 100$

As seen from this figure, the adsorption increases with increasing $\mathrm{pH}$, which suggests that adsorption of cationic metal ions takes place by cation exchange between metal ions and hydrogen atoms of carboxylic groups. In such adsorption of metal ions based on a cation exchange mechanism, the 2 positive charges on the divalent metal ions are neutralized by 2 carboxylic groups of these acidic polysaccharides, as shown in Scheme 4. However, in the cases of high-valent metal ions such as trivalent and tetravalent metal ions, it is difficult for all the positive charges $(+3$ and +4$)$ to be neutralized only by carboxylic groups because of the strong steric hindrance in acidic polysaccharides, crosslinked polysaccharides in particular, similar to the cases of synthetic cation exchange resins, as mentioned earlier. In such cases, the positive charges which are not neutralized by carboxylic groups are neutralized by anionic species existing in aqueous solution such as hydroxyl ions also similar to the cases mentioned earlier. These anionic species are easily exchanged by other anionic species such as arsenate and arsenite.

\section{Adsorption of Arsenic on Acidic Polysaccharide Loaded with High-Valent Metal Ions}

Figure 2 and Figure 3 show the effect of the equilibrium $\mathrm{pH}$ on the amount of adsorption of arsenate $[\mathrm{As}(\mathrm{V})]$ and arsenite $[\mathrm{As}(\mathrm{III})]$, respectively, on pectic acid 


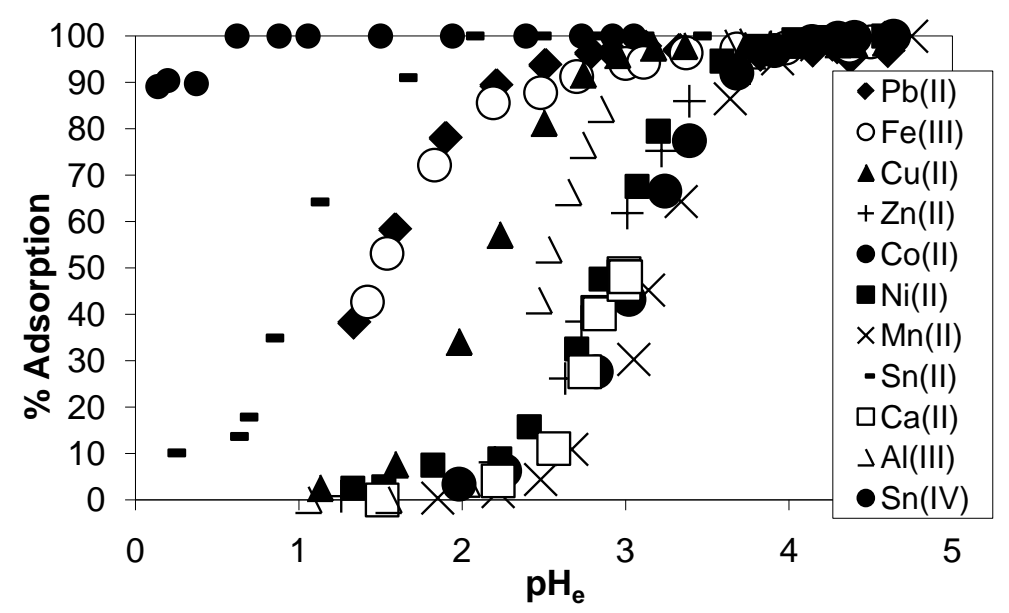

Figure 1. \% adsorption of some metal ions on pectic acid crosslinked using formaldehyde from aqueous solution at various $\mathrm{pH}$ values [13] (Reproduced with permission from The Society of Chemical Engineers, Japan).

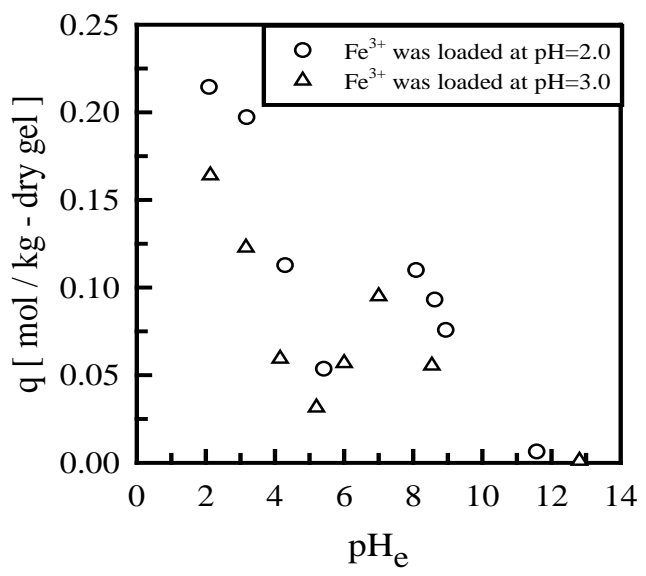

Figure 2. Adsorption amount of $\operatorname{arsenic}(\mathrm{V})(\mathrm{q})$ on pectic acid gel crosslinked using formaldehyde loaded with iron (III) at various equilibrium $\mathrm{pH}$ values. Initial arsenic concentration $=15 \mathrm{mg} \cdot \mathrm{dm}^{-3}$, temperature $=30^{\circ} \mathrm{C}[13](\mathrm{Re}-$ produced with permission from The Society of Chemical Engineers, Japan).

gel crosslinked using formaldehyde loaded with iron(III) at $\mathrm{pH} 2$ and 3 [13]. Here, the amount of adsorption was evaluated as follows.

Amount of adsorption $(q)=($ initial concentration - equilibrium concentration $)$ $\times$ volume of test solution/dry weight of adsorption gel

Figure 5 shows the amount of adsorption of $\operatorname{arsenic}(\mathrm{V})$ on pectic acid gel crosslinked using formaldehyde loaded with iron(III) at $\mathrm{pH} 3$, at various equilibrium $\mathrm{pH}$ values, from aqueous solutions in which a 10 -fold excess concentration of chloride and/or sulfate ions coexists together with that from the individual solution for comparison [13]. As seen from this figure, the coexistence of 


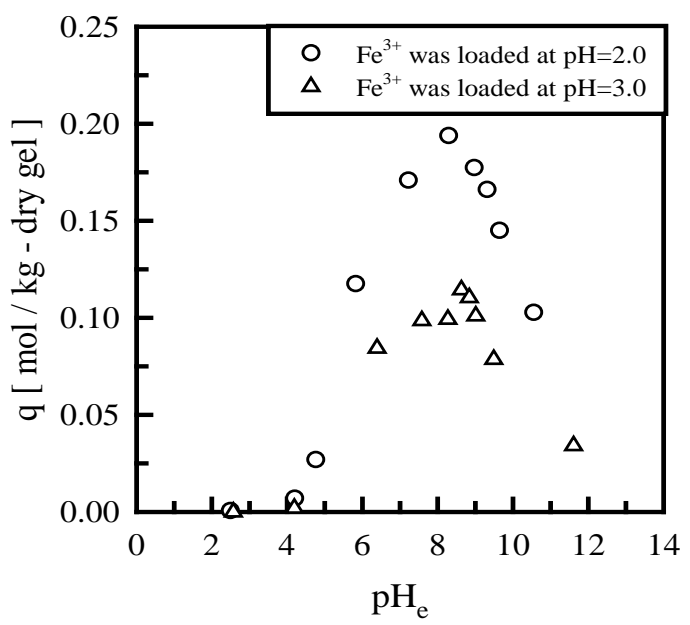

Figure 3. Adsorption amount of arsenic(III) (q) on pectic acid gel crosslinked using formaldehyde loaded with iron(III) at various equilibrium $\mathrm{pH}$ values. Initial arsenic concentration $=15 \mathrm{mg} \cdot \mathrm{dm}^{-3}$, temperature $=30^{\circ} \mathrm{C}[13]$ (Reproduced with permission from The Society of Chemical Engineers, Japan).

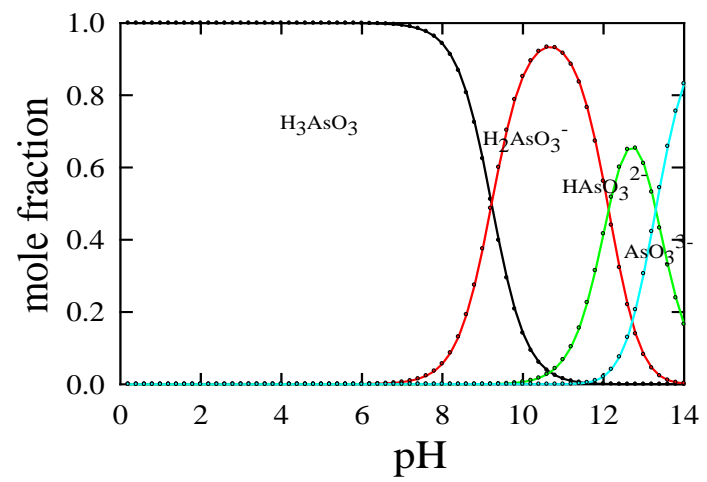

Figure 4. Distribution of arsenite [As(III)] species at various $\mathrm{pH}$ values.

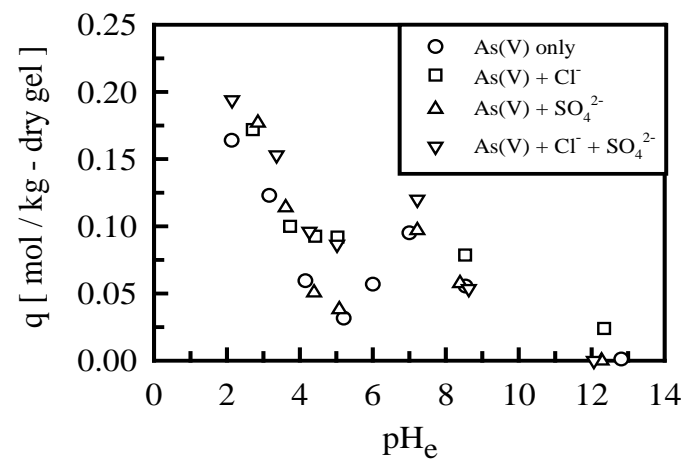

Figure 5. Effect of coexisting anionic species on the adsorption of arsenic $(\mathrm{V})$ on pectic acid gel crosslinked using formaldehyde loaded with iron(III) at $\mathrm{pH} 3$ at various equilibrium $\mathrm{pH}$ values [13] (Reproduced with permission from The Society of Chemical Engineers, Japan). 
chloride and sulfate ions only negligibly influences the adsorption of arsenic(V). A similar result was observed also in the case of the adsorption of arsenic(III). Hence, it can be concluded that an iron(III)-loaded pectic acid gel exhibits a high selectivity for arsenic(V and III).

Figure 6 shows a comparison of the amount of adsorption of arsenic(V) on a commercially available adsorbent, Unicelex UR-3700, which is a plastic porous resins containing fine powders of hydroxyl ferric oxide, with that on crosslinked pectic acid gel loaded with iron(III) at various equilibrium $\mathrm{pH}$ values. As seen from this figure, the crosslinked pectic acid gel, prepared from a natural material, gives a higher adsorption than the commercially available synthetic resin prepared from petroleum.

In both figures, the adsorption decreases with increasing $\mathrm{pH}$ at $\mathrm{pH}$ higher than 8 which is attributable to the increased concentration of hydroxyl ions, which compete with anionic arsenic species, as shown in Scheme 2. The decreasing adsorption of arsenite with decreasing $\mathrm{pH}$ at $\mathrm{pH}$ lower than 8 in Figure 3 is considered to be attributable to a decrease in the fraction of dissociated $\mathrm{H}_{2} \mathrm{AsO}_{3}^{-}$ species, or an increase in the concentrations of undissociated $\mathrm{H}_{3} \mathrm{AsO}_{3}$ species, which do not interact with the loaded iron(III) ions as shown in Figure 4. However, the adsorption of arsenate $[\mathrm{As}(\mathrm{V})]$ shown in Figure 2, is complicate, i.e., the adsorption decreases with increasing $\mathrm{pH}$ at $\mathrm{pH}$ lower than 5 while it increases with increasing $\mathrm{pH}$ at $\mathrm{pH}$ higher than 5 and again decreases at $\mathrm{pH}$ higher than 8. In both Figure 2 and Figure 3, the adsorption on the gel loaded with iron(III) at $\mathrm{pH} 3$ is lower than that loaded at $\mathrm{pH} 2$, which is considered to be attributable to the following. Since iron(III) is easily hydrolyzed even at low $\mathrm{pH}$, some portion of the iron(III) loaded at $\mathrm{pH} 3$ is hydrolyzed to fine particles of ferric hydroxide and drops off from the gel, resulting in a decrease in the amount of loaded iron(III) ions, causing a decrease in the adsorption of both arsenate and arsenite.

\section{Adsorptive Removal of Arsenic Using Orange Waste Gel Loaded with High-Valent Metal Ions}

Although, as demonstrated above, crosslinked pectic acid gel exhibits good adsorption for arsenic, it is expensive to commercially produce the gel using pure pectic acid. Consequently, we hit upon the idea of preparing similar gels using biomass wastes containing large amount of pectic acid at low cost. One candidate biomass wastes was orange juice residue.

As demonstrated in Scheme 6, adsorption gels can be easily prepared from orange juice residue just after juicing in a simple manner at cheap cost. Orange juice is produced from whole oranges by mechanically peeling followed by juicing. For one orange, one half is converted into orange juice and the other half is orange juice residue, which consists of thick outer rind, thin inner peel, seeds and calyces. In Japan, orange juice residue (OJR) is now used as cattle feed and fertilizer. Its main components are polysaccharides such as cellulose and pectin, 


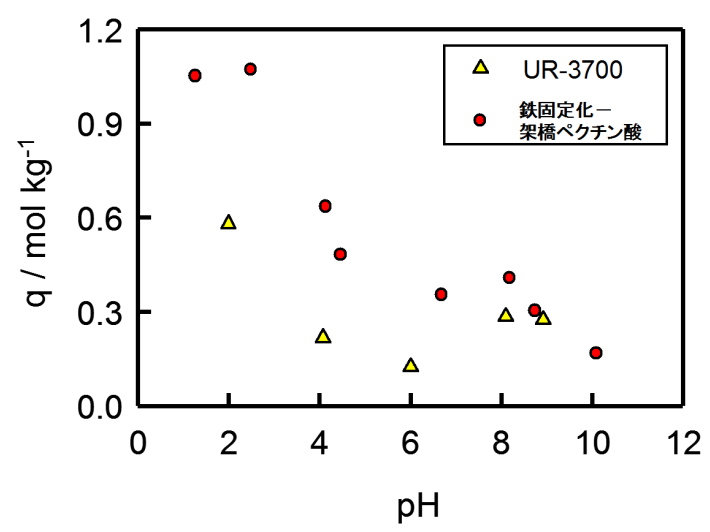

Figure 6. Amount of adsorption of arsenic (V) on commercially available adsorbent, Unicelex UR-3700, $(\boldsymbol{\Delta})$ and that on crosslinked pectic acid gel loaded with iron(III) $(\bullet)$ at various equilibrium $\mathrm{pH}$ values.

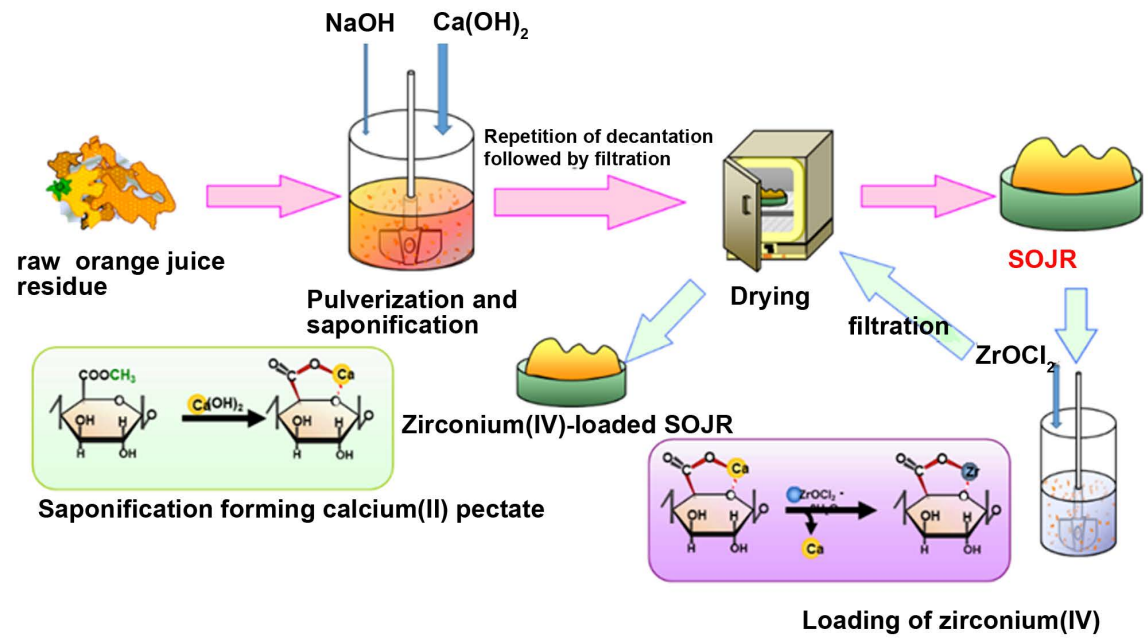

Scheme 6. Preparation of saponified orange juice residue (SOJR) gel and zirconium (IV)-loaded SOJR gel.

as mentioned earlier. To prepare the adsorption gel, OJR was treated with calcium hydroxide to increase the amount of carboxylic acid functional groups, to improve the adsorption capacity for metal ions, by the saponification reaction shown in Scheme 5, as in the following example. About $100 \mathrm{~g}$ of OJR, just after juicing, along with $8 \mathrm{~g}$ of calcium hydroxide were pulverized into small particles in a juicer mixer. The resulting mixture was transferred into a beaker, and a substantial amount of water was added. The mixture was stirred for $24 \mathrm{~h}$ at about $200 \mathrm{rpm}$ at room temperature to facilitate the saponification reaction. Here, the initial $\mathrm{pH}$ of the mixture was maintained at around 12.5 by adding sodium hydroxide solution. After decantation, the mixture was repeatedly washed with water and decanted until neutral $\mathrm{pH}$. Here, water washing is important because orange juice residue contains citric acid, which functions as a water-soluble chelating agent, impeding adsorption of metal ions or eluting the loaded metal ions. The mixture was finally filtered to obtain wet gel, which was dried in a convec- 
tion oven for about $48 \mathrm{~h}$ at $70^{\circ} \mathrm{C}$ to obtain a dry gel. Thus prepared dry gel is abbreviated as SOJR (Saponified Orange Juice Residue), hereafter. Figure 7 shows a scanning electron microscope (SEM) image of the prepared SOJR. The specific surface area of this gel was measured to be $7.25 \mathrm{~m}^{2} \cdot \mathrm{g}^{-1}$.

In the SOJR, pectic acid is present as calcium pectinate, which can be converted into the free acid form, for example, by washing with $0.1 \mathrm{~mol} \cdot \mathrm{dm}^{-3}$ hydrochloric acid followed by washing with water until neutral $\mathrm{pH}$. The prepared free acid form of the SOJR was found to contain $2.69 \mathrm{~mol} \cdot \mathrm{kg}^{-1}$ of hydrogen ions while the gel prepared from pure pectic acid gel, mentioned earlier, was found to contain $5.65 \mathrm{~mol} \cdot \mathrm{kg}^{-1}$ of free hydrogen ions, which suggests that a much cheaper adsorbent possessing the same functional groups can be produced from biomass waste [14].

Figure 8 shows the adsorption behavior of the SOJR gel for some metal ions as plots of \% adsorption vs equilibrium $\mathrm{pH}$ [14]. As seen from this figure, zirconium(IV), iron(III), lead(II) and copper(II) are selectively and strongly adsorbed on this gel. Iron(III) was found to be adsorbed according to the Langmuir's adsorption isotherm, from which the maximum adsorption capacity for iron(III) was evaluated as $1.55 \mathrm{~mol} \cdot \mathrm{kg}^{-1}$, while that on the crosslinked pectic acid gel was evaluated as $0.57 \mathrm{~mol} \cdot \mathrm{kg}^{-1}$, which is inferred to be attributable to the effect of calcium(II) ions in the SOJR gel, i.e., it is inferred that iron(III) ions were hydrolyzed to fine particles of ferric hydroxide, which remain in the SOJR gel.

A similar adsorption gel was prepared also from apple juice residue [15].

Figure 9 shows the removal \% or \% adsorption of arsenic(III and V) using iron(III)-loaded SOJR gel at various $\mathrm{pH}$ values, and removal of arsenic(V) by a conventional coprecipitation method with iron(III) for comparison. As seen from this figure, $\operatorname{arsenic}(\mathrm{V})$ can be nearly quantitatively removed over a wide $\mathrm{pH}$ range (pH 2 - 6). More than $80 \%$ of arsenic(III) can be removed at pH 7 - 9 using iron(III)-loaded SOJR gel, while the conventional coprecipitation method using iron(III) chloride can remove more than $80 \%$ of arsenic(V) only in a relatively narrow $\mathrm{pH}$ range ( $\mathrm{pH} 5$ - 6).

Figure 10 and Figure 11 illustrate the \% adsorption or removal \% of arsenic(V) and arsenic(III), respectively, on SOJR gel loaded with iron(III), cerium(III) or zirconium(III) at various equilibrium $\mathrm{pH}$ values, to show the effect of the

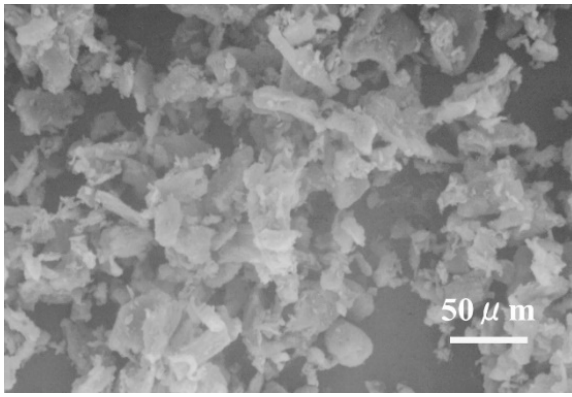

(a)

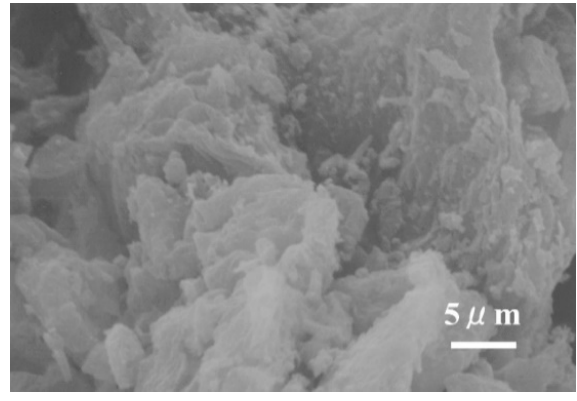

(b)

Figure 7. Scanning electron microscope image of SOJR gel. 


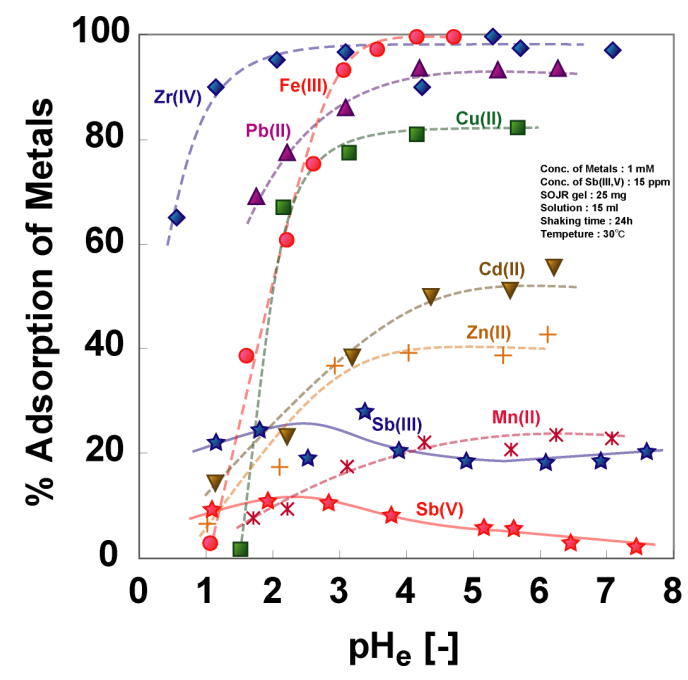

Figure 8. \% adsorption (R\%) of some metal ions on SOJR gel at various equilibrium $\mathrm{pH}$ values [14].

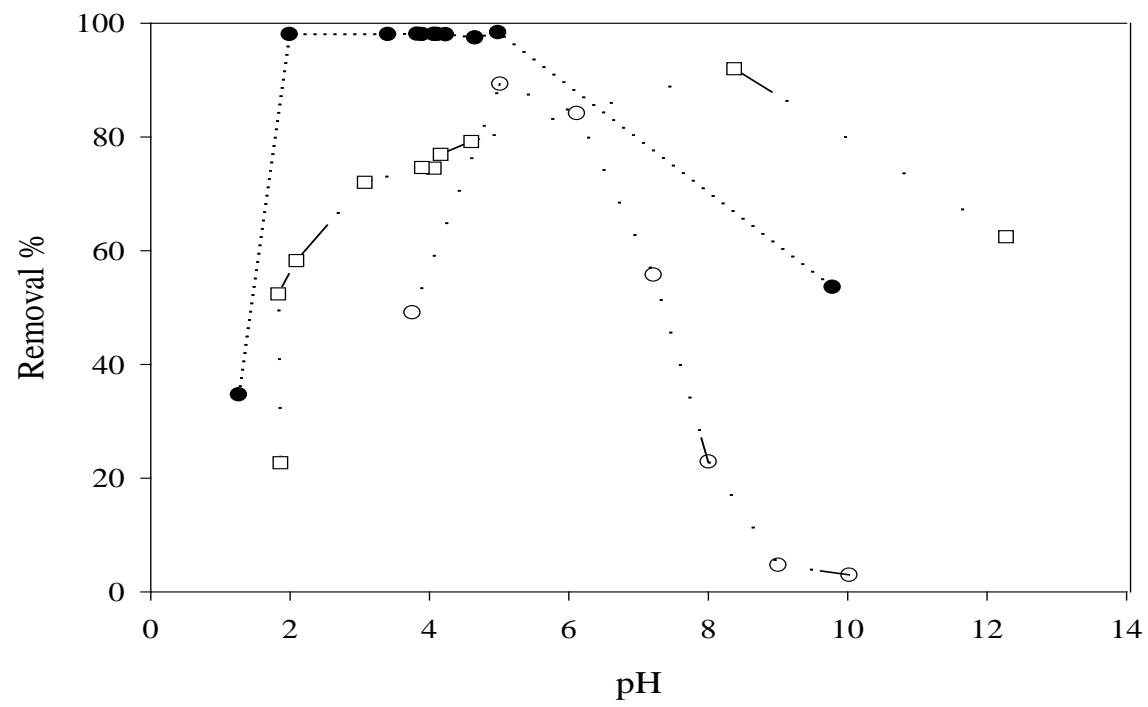

Figure 9. Removal \% or \% adsorption of arsenic(III and V) using iron(III)-loaded SOJR gel and removal of arsenic(V) by a coprecipitation method with iron(III) at various $\mathrm{pH}$ values. •: removal of arsenic(V) using iron(III)-loaded SOJR gel, $\square$ : removal of arsenic(III) using iron(III)-loaded SOJR gel, O: removal of arsenic(V) by means of coprecipitation method using iron(III) chloride [7] (Reproduced with permission from The Mining and Materials Processing Institute of Japan).

loaded metal ions [16]. As can be seen from this figure, the effect of the $\mathrm{pH}$ differs greatly depending on the loaded metal ions for both arsenic(III) and arsenic(V). Zirconium(IV)-loaded SOJR can remove both arsenic species over a wider $\mathrm{pH}$ range than iron(III)- and cerium(III)-loaded SOJR gels, suggesting that zirconium(IV) is the most suitable loaded metal ion on the SOJR gel.

Zirconium(IV) ions have another advantage over other metal ions as the loaded metal ion. Figure 12 shows the \% leakage of the loaded metal ions from the SOJR gel at various equilibrium $\mathrm{pH}$ values. As can be seen from this figure, 


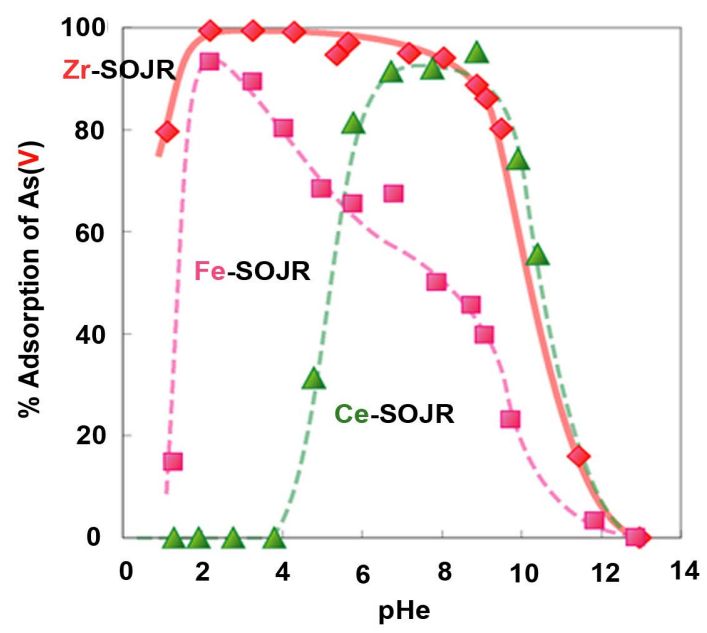

Figure 10. \% adsorption of arsenic(V) on SOJR gel loaded with iron(III), cerium(III) or zirconium(IV) at various equilibrium $\mathrm{pH}$ values [16].

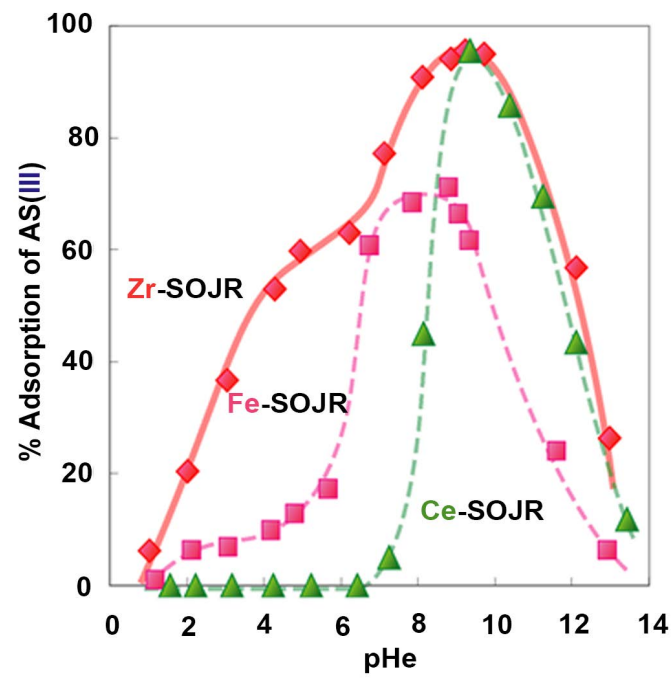

Figure 11. \% adsorption of arsenic(III) on SOJR gel loaded with iron(III), cerium(III) or zirconium(IV) at various equilibrium $\mathrm{pH}$ values [16].

although some portions of the loaded iron(III) and cerium(III) leak from the SOJR gel, at low $\mathrm{pH}$ in particular, the leakage of zirconium(IV) is negligible.

Figure 13 and Figure 14 show the effects of other anionic species, namely chloride, sulfate and carbonate, which usually coexist together with arsenic in actual aqueous solutions, on the \% adsorption of arsenic(V) and arsenic(III), respectively, on zirconium(IV)-loaded SOJR gel at various $\mathrm{pH}$ values [16]. As can be seen from these figures, excess concentrations of these coexisting anionic species only negligibly influence the adsorption of both arsenic(V) and arsenic(III), suggesting high selectivity of this adsorbent for arsenic.

Figure 15 shows the adsorption isotherms of arsenic(V and III) on zirconium(IV)-loaded SOJR gel ( $\mathrm{Zr}$-SOJR) together with those for zirconium ferrite 


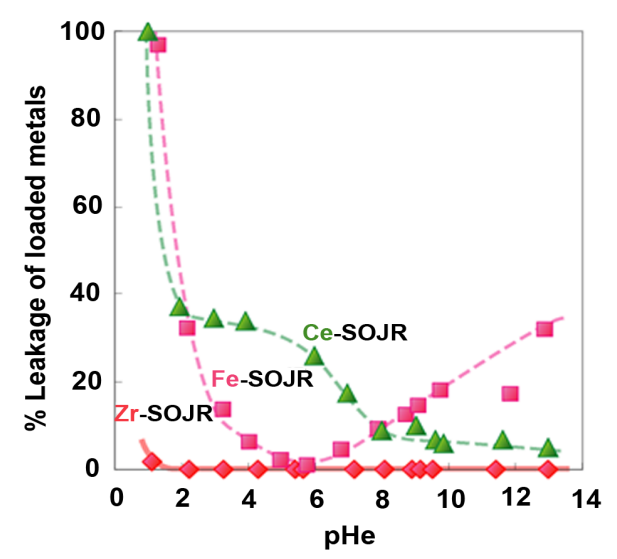

Figure 12. \% leakage of loaded metal ions from SOJR gel at various equilibrium $\mathrm{pH}$ values [16].

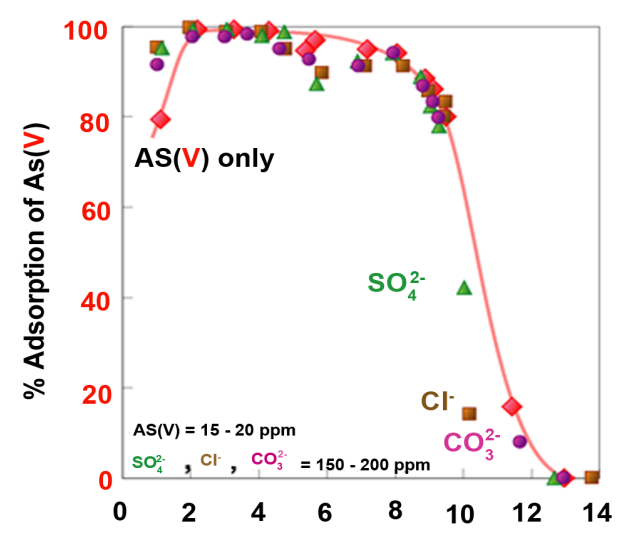

Figure 13. \% adsorption of $\operatorname{arsenic}(\mathrm{V})$ on SOJR gel loaded with zirconium(IV) ions from aqueous solutions containing arsenic(V) and about 10-fold excess concentrations of chloride, sulfate and carbonate [16].

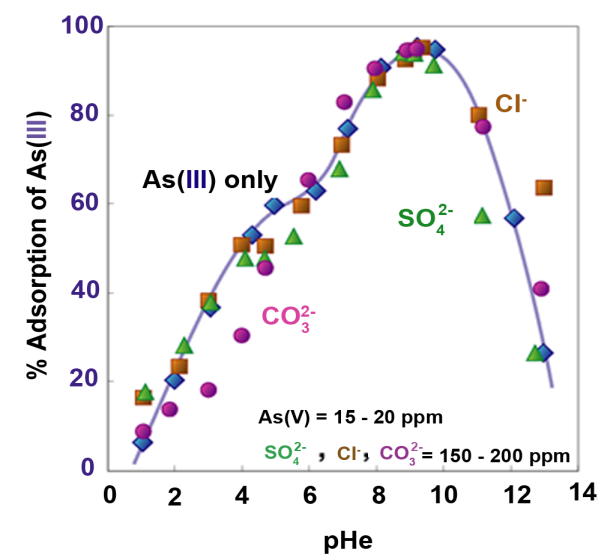

Figure 14. \% adsorption of arsenic(III) on SOJR gel loaded with zirconium(IV) ions from aqueous solutions containing arsenic(III) and about 10 -fold excess concentrations of chloride, sulfate and carbonate [16]. 


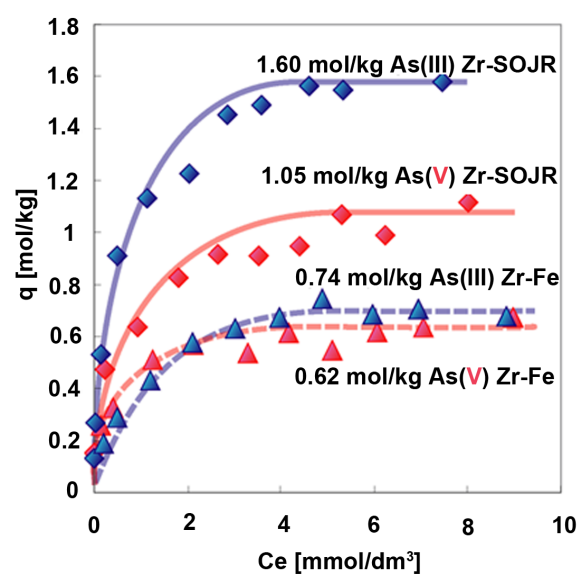

Figure 15. Adsorption isotherms of arsenic( $\mathrm{V}$ and III) on zirconium(IV)-loaded SOJR gel (Zr-SOJR) and on zirconium ferrite $(\mathrm{Zr}-\mathrm{Fe})$.

(Zr-Fe), a commercially available inorganic adsorbent, the chemical composition of which is $\mathrm{ZrFe}_{2}(\mathrm{OH})_{8}$. All the adsorption isotherms in this figure are the Langmuir-type adsorption isotherm; the constant values of the plateau regions of these isotherms were used to evaluate the maximum adsorption capacities for arsenic(III and V), as shown in this figure. It is obvious from this figure that the adsorption capacities on zirconium(IV)-loaded SOJR gel are higher than that on commercially available zirconium ferrite for both arsenic(III) and arsenic(V) and that the adsorption capacities for arsenic(III) are higher than those for arsenic(V) for both adsorbent. These values are also listed in Table 1 together with values reported in the literatures for comparison.

On the basis of the information on the fundamental adsorption behavior for anionic species of arsenic(V and III) obtained by batch-wise experiments, continuous adsorption followed by elution tests were carried out using a glass column shown in Figure 16.

Figure 17 shows breakthrough profiles of $\operatorname{arsenic}(\mathrm{V})$ and arsenic(III) from a column packed with zirconium(IV)-loaded SOJR gel for individual feed solutions of arsenic(V) and arsenic(III) under the condition given in the figure legend. In this figure, the ordinate denotes the ratio of the outlet concentration $(C)$ to the inlet concentration $\left(C_{0}\right)$ and the abscissa denotes the bed volume (B.V.), which is defined as the ratio of the volume of feed solution which passed through the adsorption bed packed in the column to the volume of adsorbent packed in the column (i.e. the contact time during adsorption or elution). Both arsenic species can be completely removed until about 600 B.V.

Figure 18 shows the elution profiles of arsenic(III and V) using $0.5 \mathrm{~mol} \cdot \mathrm{dm}^{-3}$ sodium hydroxide solution from the loaded column after the complete breakthrough shown in Figure 17. From this figure, it is evident that arsenic(V) and arsenic(III) are eluted from the column within a short time, at concentration as high as 80 and 25 times, respectively, that of the feed concentration. 
Table 1. Comparison of maximum adsorption capacities for arsenic(III and V) on some adsorbents.

\begin{tabular}{cccc}
\hline Adsorbent & $\begin{array}{c}\text { Arsenic } \\
\text { species }\end{array}$ & $\begin{array}{c}\text { Maximum adsorption } \\
\text { capacity }\left(\mathrm{mol}^{-\mathrm{kg}^{-1}}\right)\end{array}$ & Reference \\
\hline Zr(IV)-loaded SOJR & As(V) & 1.05 & {$[17]$} \\
Zirconium ferrite & As(V) & 0.62 & This work \\
Activated carbon & As(V) & 0.014 & {$[18]$} \\
La(III)-impregnated alumina & As(V) & 0.171 & {$[19]$} \\
Ce(IV)-doped iron oxide & As(V) & 0.213 & {$[20]$} \\
Zr(IV)-loaded LDA chelating resin & As(V) & 0.655 & {$[21]$} \\
Lessonia nigrescens, an algae & As(V) & 0.376 & {$[22]$} \\
Zr(IV)-loaded SOJR & As(III) & 1.60 & {$[17]$} \\
Zirconium ferrite & As(III) & 0.74 & This work \\
Fe(III)-loaded LDA chelating resin & As(III) & 0.839 & {$[23]$} \\
Fe(III)-loaded phosphorylated orange & As(III) & 0.909 & {$[24]$} \\
juice residue & As(III) & 0.0004 & {$[25]$} \\
Iron oxide-coated sand & As(III) & 0.0098 & {$[26]$} \\
Polymetallic sea nodule & As(III) & 0.0092 & {$[27]$} \\
Iron oxide coated cement & As(III) & 0.048 & {$[28]$} \\
Sorghum biomass & &
\end{tabular}

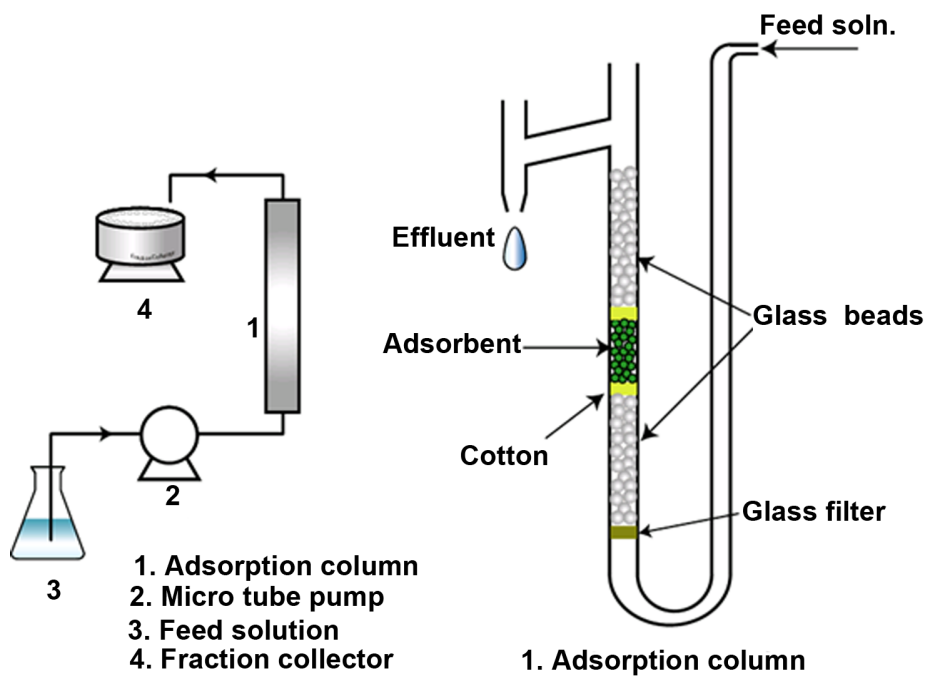

Figure 16. Schematic diagram of the glass column employed in the experiments for continuous adsorption followed by elution.

Figure 19 shows the results of cyclic operation of adsorption of $\operatorname{arsenic}(\mathrm{V})$ followed by elution using $0.5 \mathrm{~mol} \cdot \mathrm{dm}^{-3}$ sodium hydroxide solution by a column packed with zirconium(IV)-loaded SOJR gel up to 5 cycles. Although both the $\%$ adsorption and elution are slightly lower after the second cycle, they are still higher than $80 \%$, suggesting high durability of the zirconium(IV)-loaded SOJR gel for repeated use for a long time. 


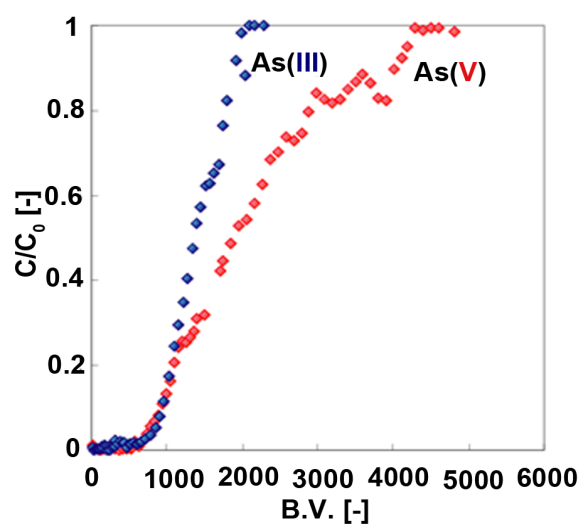

Figure 17. Examples of breakthrough profiles of arsenic(III and V) from the packed column shown in Figure 16. Conditions: feed concentration $\left(C_{0}\right)=$ $4.8 \mathrm{mg} \cdot \mathrm{dm}^{-3}$, dry weight of the packed gel $=0.1 \mathrm{~g}$, feed rate $=6.5 \mathrm{~cm}^{3} \cdot \mathrm{h}^{-1}$ for $\operatorname{arsenic}(\mathrm{V}), 3.3 \mathrm{~cm}^{3} \cdot \mathrm{h}^{-1}$ for arsenic(III), and $\mathrm{pH}$ of the feed solution $=3.3$ for $\operatorname{arsenic}(\mathrm{V})$ and 9.1 for $\operatorname{arsenic}(\mathrm{III})$ [16].

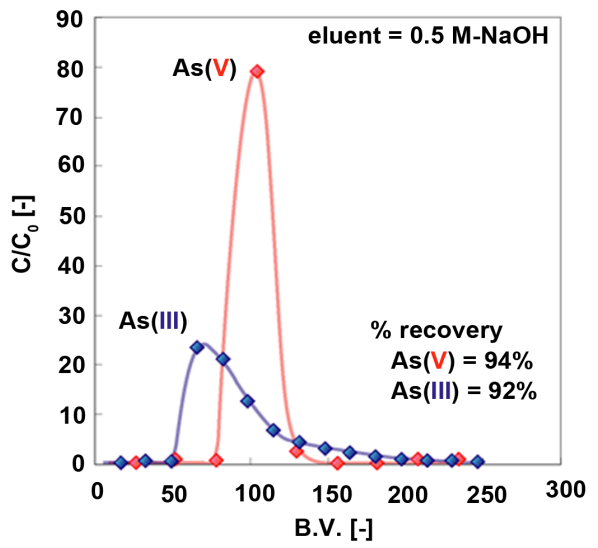

Figure 18. Elution profiles of arsenic(III and V) from the loaded column after the break through shown in Figure 17 [16].

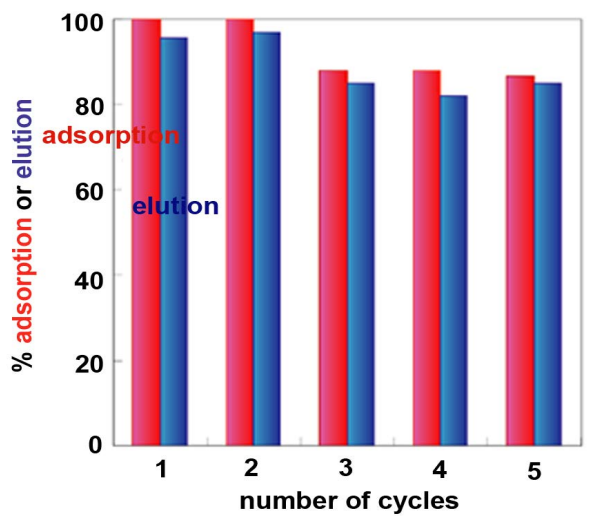

Figure 19. Results of cyclic operation of adsorption of arsenic(V) followed by elution using a column packed with zirconium(IV)-loaded SOJR gel [16]. 


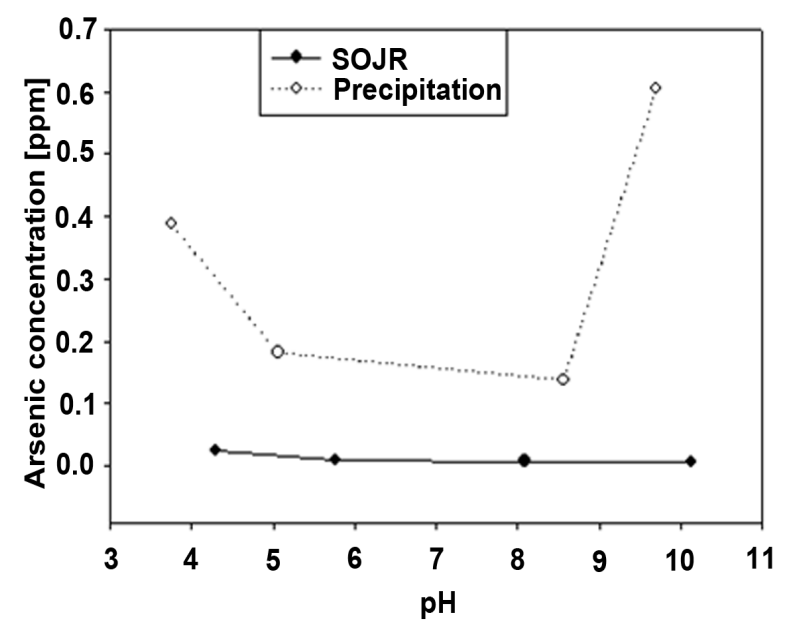

Figure 20. Removal of arsenic from actual acid mine drainage at Horobetsu mine in Hokkaido, Japan, by conventional coprecipitation method and adsorption using SOJR gel, as plots of arsenic concentration after the treatments vs $\mathrm{pH}$ [7] (Reproduced with permission from The Mining and Materials Processing Institute of Japan).

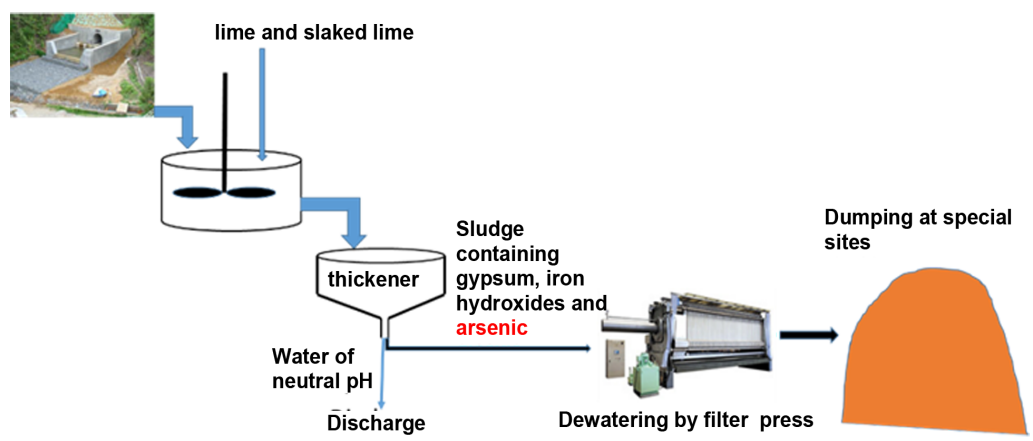

(a)

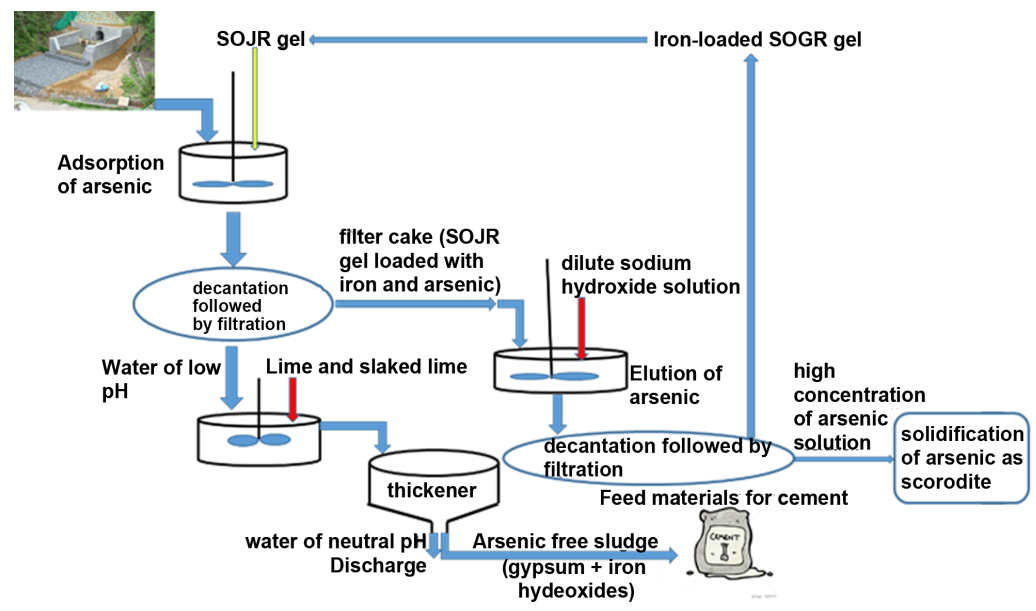

(b)

Scheme 7. Schematic flowsheets of processes for arsenic removal from acid mine drain age from Horobetsu mine: (a) Currently used process; (b) New process using SOJR gel. 
The effectiveness of the SOJR gel was further confirmed by testing the removal of arsenic from an actual solution using arsenic-containing acid mine drainage from the Horobetsu mine mentioned in the Introduction [7]. Since, as mentioned earlier, this solution contains a high concentration of iron (total iron concentration $=336 \mathrm{mg} \cdot \mathrm{dm}^{-3}$ ), increasing the $\mathrm{pH}$ results in formation of precipitates of iron hydroxide with which arsenic is coprecipitated. In this test, SOJR gel was added without loading metal ions, since a large amount of iron ion was expected to be adsorbed onto the added SOJR gel prior to the adsorption of arsenic.

Figure 20 shows plots of the total concentration of arsenic after treatments using the SOJR gel and without using the gel, i.e., treatment by coprecipitation method by adding sodium hydroxide, for comparison, at various $\mathrm{pH}$ values. As can be seen from this figure, nearly quantitative removal of arsenic was achieved by adding SOJR gel over the whole $\mathrm{pH}$ range tested, including low $\mathrm{pH}$ values such as $\mathrm{pH} 4$, while a higher concentration of arsenic still remained after the treatment without using the SOJR, or by the currently used treatment.

In the currently used treatment mentioned in the Introduction, lime (calcium carbonate) and slaked lime (calcium hydroxide) are used to increase the $\mathrm{pH}$ value since the $\mathrm{pH}$ value in the feed solution is as low as 1.8 . Consequently, the addition of lime and slaked lime results in the generation of a huge amount of precipitated water-insoluble gypsum (calcium sulfate) since the solution also contains a high concentration of sulfate $\left(2510 \mathrm{mg} \cdot \mathrm{dm}^{-3}\right)$. Arsenic coprecipitated onto precipitates of iron hydroxide is dumped together with this huge amount of gypsum after dewatering using filter press machines at special dumping sites. If arsenic were removed in advance prior to neutralization of the acid mine drainage, the gypsum would be free from arsenic contamination and able to be marketed as feed materials for cement and construction materials such as gypsum board as illustrated in Scheme 7.

\section{Conclusion}

Environmentally benign adsorption gel was found to be prepared in a simple manner from juice residues of oranges and apples. By loading high-valent metal ions such as iron(III), rare earths(III) and zirconium(IV) on these gels, low or trace concentrations of arsenic(III and IV) was effectively and selectively removed from water. Among these loaded high-valent metal ions, zirconium(IV) was found to be the most suitable. The effectiveness of such metal-loaded gel was verified for the actual solution of acid mine drainage.

\section{References}

[1] Green Facts (Facts on Health and Environment) (2004) 4.1 What Happens to Arsenic Absorbed by the Body? https://www.greenfacts.org/en/arsenic/1-2/arsenic-7/htm

[2] Lenoble, V., Chabroullet, C., Al-Shukry, R., Serpaud, B., Deluchat, V. and Bollinger, J.C. (2004) Dynamic Arsenic Removal on a $\mathrm{MnO}_{2}$-Loaded Resin. Journal of Colloid 
and Interface Science, 280, 62-67. https://doi.org/10.1016/j.jcis.2004.07.034

[3] Huang, C.P. and Fu, P.L.K. (1984) Treatment of Arsenic(V)-Containing Water by the Activated Carbon Process. Journal of Water Pollution Control Federation, 56, 233-242.

[4] Smedley, P.L. and Kinniburgh, D.G. (2002) A Review of the Source, Behavior and Distribution of Arsenic in Natural Water. Applied Geochemistry, 17, 517-568. https://doi.org/10.1016/S0883-2927(02)00018-5

[5] Twindwell, L.G., Robins, R.G. and Hohn, J.W. (2005) The Removal of Arsenic from Aqueous Solution by Coprecipitation with Iron(III) In: Reddy, R.G. and Ramachandran, V., Eds., Arsenic Metallurgy, The Minerals, Metals \& Materials Society (TMS), John Wiley \& Sons, Inc. Warrendale, PA, 3-24.

[6] Japan Oil, Gas and Metals National Corporation (JOGMEC) and DOWA Techno Electric \& Engineering Company Ltd. (2012) Outline of the Development of Advanced Technology for the Treatment of Acid Mine Drainage. (In Japanese) http://www.meti.go.jp/policy/tech_evaluation/c00/C0000000H24/130117_sensin2/s enshin2_sanko.pdf

[7] Inoue, K., Ghimire, K.N., Hayashida, T., Oshima, T., Ohto, K., Makino, K., Kuboki, E. and Hashimoto, K. (2003) Removal of Arsenic from Mine Water by the Effective Use of Biomass. Shigen to Sozai (Journal of the Mining and Materials Processing Institute of Japan), 119, 767-771. (In Japanese)

[8] Yoshida, I., Ueno, K. and Kobayashi, H. (1978) Selective Separation of Arsenic(III and V) Ions with Ferric Complex of Chelating Ion-Exchange Resin. Separation Science and Technology, 13, 173-184. https://doi.org/10.1080/01496397808057099

[9] Dhakal, R.P., Ghimire, K.N., Inoue, K., Yano, M. and Makino, K. (2005) Acidic Poly Saccharide Gels for Selective Adsorption of Lead(II) Ion. Separation and Purification Technology, 42, 219-224. https://doi.org/10.1016/j.seppur.2004.07.016

[10] Inoue, K., Baba, Y. and Yoshizuka, K. (1993) Adsorption of Metal Ions on Chitosan and Crosslinked Copper(II)-Complexed Chitosan. Bulletin of the Chemical Society of Japan, 66, 2915-2921. https://doi.org/10.1246/bcsj.66.2915

[11] Maruyama, T., Matsushita, H., Shimada, Y., Kamata, I., Hanaki, M., Sonokawa, S., Kamiya, N. and Goto, M. (2007) Proteins and Protein-Rich Biomass as Environmentally Friendly Adsorbents Selective for Precious Metal Ions. Environmental Science \& Technology, 41, 1359-1364. https://doi.org/10.1021/es061664x

[12] Kuyucal, N. and Volesky, B. (1988) Biosorbents for Recovery of Metals from Industrial Solutions. Biotechnology Letters, 10, 137-142.

https://doi.org/10.1007/BF01024641

[13] Inoue, K., Shioya A., Zhu, Y., Sedlackova, I., Makino, K. and Baba, Y. (2003) Adsorptive Removal of Arsenic by Ferric Ion-Loaded Crosslinked Pectic Acid Gel. Kagaku Kogaku Ronbunshu, 29, 389-394. (In Japanese) https://doi.org/10.1252/kakoronbunshu.29.389

[14] Dhakal, R.P., Ghimire, K.N. and Inoue, K. (2005) Adsorptive Separation of Heavy Metals from an Aquatic Environment Using Orange Waste. Hydrometallurgy, 79, 182-190. https://doi.org/10.1016/j.hydromet.2005.06.007

[15] Inoue, K., Ghimire, K.N. and Makino, K. (2003) Removal of Impurity Metal Ions from Waste Plating Solutions by Using Orange and Apple Juice Residues. In: Schlesinger, M.E., Ed., EPD Congress 2003, The Minerals, Metals \& Materials Society (TMS), Warrendale, 525-535.

[16] Inoue, K. (2008) Adsorptive Removal of Hazardous Inorganic Elements from Water 
by Using Orange Waste. Indonesian Journal of Chemistry, 8, 293-299.

[17] Biswas, B.K., Inoue, J., Inoue, K., Ghimire, K.N., Harada, H., Ohto, K. and Kawakita, H. (2008) Adsorptive Removal of As(V) and As(III) from Water by a $\mathrm{Zr}$ (IV)-Loaded Orange Waste Gel. Journal of Hazardous Materials, 154, 1066-1074. https://doi.org/10.1016/j.jhazmat.2007.11.030

[18] Gupta, S.K. and Chen, K.Y. (1978) Arsenic Removal by Adsorption. Journal of the Water Pollution Control Federation, 50, 493-506.

[19] Wasay, S.A., Tokunaga, S. and Park, S.W. (1996) Removal of Hazardous Anions from Aqueous Solutions by La(III) and Y(III)-Impregnated Alumina. Separation Science and Technology, 31, 1501-1514. https://doi.org/10.1080/01496399608001409

[20] Zhang, Y., Yang, M. and Huang, X. (2003) Arsenic(V) Removal with a Ce(IV)-Doped Iron Oxide Adsorbent. Chemosphere, 51, 945-952. https://doi.org/10.1016/S0045-6535(02)00850-0

[21] Balaji, T., Yokoyama, T. and Matsunaga, H. (2005) Adsorption and Removal of $\mathrm{As}(\mathrm{V})$ and As(III) Using Zr-Loaded Lysine Diacetic Acid Chelating Resin. Chemosphere, 59, 1169-1174. https://doi.org/10.1016/j.chemosphere.2004.12.007

[22] Hansen, H.K., Ribeiro, A. and Mareus, E. (2006) Biosorption of Arsenic(V) with Les sonia nigrescens. Minerals Engineering, 19, 486-490. https://doi.org/10.1016/j.mineng.2005.08.018

[23] Matsunaga, H., Yokoyama, T., Eldridge, R.J. and Bolto, B.A. (1996) Adsorption Characteristics of Arsenic(III) and Arsenic(V) on Iron(III)-Loaded Chelating Resin Having Lysine-N,N-Diacetic Acid Moiety. Reactive \& Functional Polymers, 29, 167-174. https://doi.org/10.1016/1381-5148(96)00041-7

[24] Ghimire, K.N., Inoue, K., Makino, K. and Miyajima, T. (2002) Adsorptive Removal of Arsenic Using Orange Juice Residue. Separation Science and Technology, 37, 2785-2799. https://doi.org/10.1081/SS-120005466

[25] Gupta, V.K., Saini, V.K. and Jain, N. (2005) Adsorption of As(III) from Aqueous Solutions by Iron Oxide-Coated Sand. Journal of Colloid and Interface Science, 288, 55-60. https://doi.org/10.1016/j.jcis.2005.02.054

[26] Maity, S., Chakravarty, S., Bhattacharjee, S. and Roy, B.C. (2005) A Study on Arsenic Adsorption on Polymetallic Sea Nodule in Aqueous Medium. Water Research, 39, 2579-2590. https://doi.org/10.1016/j.watres.2005.04.054

[27] Kundu, S. and Gupta, A.K. (2007) Adsorption Characteristics of As(III) from Aqueous Solution on Iron Oxide Coated Cement. Journal of Hazardous Materials, 142, 464-479. https://doi.org/10.1016/j.jhazmat.2006.07.059

[28] Haque, M.N., Morrison, G.M., Perrusquia, G., Gutierrez, M., Aguilera, A.F., Aguilera, I.C. and Torresdey, J.L.G. (2007) Characteristics of Arsenic Adsorption to Sorghum Biomass. Journal of Hazardous Materials, 145, 30-35.

https://doi.org/10.1016/j.jhazmat.2006.10.080 